\title{
Impact of retained blood requiring reintervention on outcomes after cardiac surgery
}

Felix Balzer, MD, MSc, ${ }^{\mathrm{a}}$ Christian von Heymann, MD, PhD ${ }^{\mathrm{a}, \mathrm{b}}$ Edward M. Boyle, MD, ${ }^{\mathrm{c}}$ Klaus D. Wernecke, $\mathrm{PhD},{ }^{\mathrm{d}}$ Herko Grubitzsch, $\mathrm{MD}, \mathrm{PhD},{ }^{\mathrm{e}}$ and Michael Sander, $\mathrm{MD}, \mathrm{PhD}^{\mathrm{a}, \mathrm{f}}$

\begin{abstract}
Objectives: Evacuation of shed blood from around the heart and lungs is a critical requirement for patients in early recovery after cardiac surgery. Incomplete evacuation of shed blood can result in retained blood, which may require subsequent reinterventions to facilitate recovery. The purpose of this study was to determine the incidence of retained blood requiring reintervention and examine the impact on outcomes.
\end{abstract}

Methods: We performed a cross-sectional, observational study of all adult patients undergoing cardiac surgery between 2006 and 2013. Subjects who required an intervention to remove blood, blood clot, or bloodily fluid were attributed to the retained blood group. These patients were compared with those not presenting with any of the defined criteria for retained blood. Multivariate regression was performed to account for confounders.

Results: Of 6909 adult patients who underwent cardiac surgery, $1316(19 \%)$ presented with a retained blood-related condition. Retained blood was associated with increased in-hospital mortality (odds ratio [OR], 4.041; 95\% confidence interval $[\mathrm{CI}], 2.589-6.351, P<.001)$ and a length of stay more than 13 days in the hospital $(\mathrm{OR}, 3.853 ; 95 \% \mathrm{CI}, 2.882-5.206 ; P<.001)$ and 5 days in the intensive care unit (OR, 4.602; 95\% CI, 3.449-6.183; $P<.001$ ). The OR for a time of ventilation greater than 23 hours was $3.596(95 \%$ CI, $2.690-4.851 ; P<.001)$ and for incidence of renal replacement therapy was 4.449 (95\% CI, 3.188-6.226; $P<.001)$.

Conclusions: Postoperative retained blood is a common outcome and associated with higher in-hospital mortality, longer intensive care unit and hospital stay, and higher incidence of renal replacement therapy. Further research is needed to validate these results and explore interventions to reduce these complications. (J Thorac Cardiovasc Surg 2016;152:595-601)

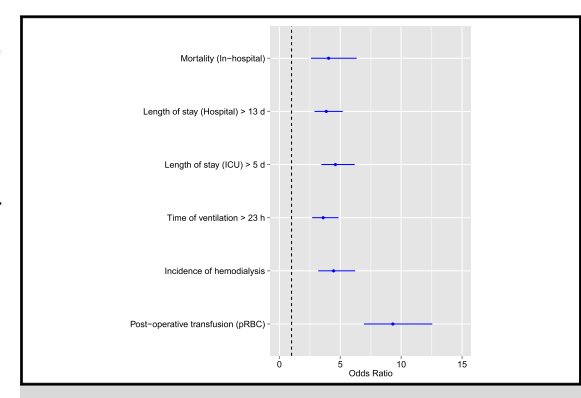

Graphical presentation of OR of selected outcome parameters with respect to retained blood.

Central Message

Postoperative retained blood is a common complication after cardiac surgery and associated with compromised outcomes.

\section{Perspective}

For patients recovering from cardiac surgery, incomplete evacuation of shed blood can result in retained blood around the heart and lungs and impaired outcomes. However, this is a potentially readily addressable problem, because methods to actively clear drains of obstructions may be targeted through protocols for quality-improvement initiatives in the ICU.

See Editorial Commentary page 602

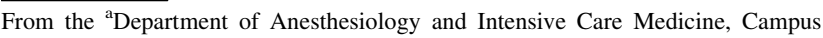
Charité Mitte and Campus Virchow-Klinikum, Charité - Universitätsmedizin; ${ }^{\mathrm{b}}$ Department of Anesthesiology, Intensive Care Medicine, Emergency and Pain Medicine, Vivantes Klinikum im Friedrichshain; 'St Charles Medical Center, Bend, Ore; ${ }^{\mathrm{d}}$ Charité - Universitätsmedizin Berlin and SOSTANA GmbH; ${ }^{\mathrm{e} D e p a r t-}$ ment of Cardiovascular Surgery, Campus Charité Mitte, Charité - Universitätsmedizin, Berlin; and ${ }^{\mathrm{f}}$ Department of Anesthesiology and Intensive Care Medicine, Universitätsklinikum Giessen und Marburg GmbH, Giessen, Germany.

This study was funded in part by a grant from ClearFlow, Inc (Anaheim, Calif). The company had no role in data collection or interpretation.

Presented at the Foundation for the Advancement of Cardiothoracic Surgical Care Cardiovascular-Thoracic Critical Care Meeting, October 10, 2014, Washington, DC.

Received for publication March 3, 2015; revisions received March 6, 2016; accepted for publication March 18, 2016; available ahead of print May 20, 2016.

Address for reprints: Felix Balzer, MD, MSc, Department of Anesthesiology and Intensive Care Medicine, Campus Charité Mitte and Campus VirchowKlinikum, Charité - Universitätsmedizin Berlin, Campus Charité Mitte, Charitéplatz 1, 10117 Berlin, Germany (E-mail: felix.balzer@charite.de). 0022-5223

Copyright (C) 2016 by The American Association for Thoracic Surgery. Published by Elsevier Inc. This is an open access article under the CC BY-NC-ND license (http:// creativecommons.org/licenses/by-nc-nd/4.0/)

http://dx.doi.org/10.1016/j.jtcvs.2016.03.086
}

Postoperative hemorrhage is one of the most common complications in patients after heart surgery. ${ }^{1}$ Existing studies identify a wide range of risk factors for bleeding, including advanced age, nonelective surgery, low body surface area, prolonged cardiopulmonary bypass time ( $>150$ minutes), complex procedures, number of bypass grafts $(>5)$, and preoperative use of antiplatelet agents. ${ }^{2-5}$ Bleeding is associated with worse outcomes, including higher 30-day mortality, higher incidence of stroke, intensive care unit (ICU) stay more than 72 hours, mechanical ventilation

Scanning this QR code will take you to supplemental tables for this article. 


\section{Abbreviations and Acronyms \\ $\mathrm{CABG}=$ coronary artery bypass grafting \\ $\mathrm{CI}=$ confidence interval \\ ICU = intensive care unit \\ $\mathrm{OR} \quad=$ odds ratio}

more than 24 hours, and significantly increased costs. ${ }^{5,6}$ The exact cause of the higher mortality and complications related to bleeding has not been elucidated completely. In theory, bleeding, as measured by output of chest tubes, should be adequately addressed in the ICU with blood transfusions, treatment with factor concentrates, and fluid resuscitation until the bleeding is treated and resolves or is corrected surgically. Yet, numerous studies demonstrate that outcomes are considerably worse in patients who are transfused with blood, leading to speculation that the poor outcomes could be related directly to the negative biologic impact of transfusions and anemia. ${ }^{7-9}$ However, several recent studies have shown that adverse clinical results and mortality due to bleeding is independent of the need for transfusions or that limiting transfusions has no beneficial effect or may even be harmful. ${ }^{10,11}$ These findings raise the possibility that there may be other mechanisms that contribute to poor outcomes in patients bleeding after heart surgery. ${ }^{6,12,13}$

One mechanism by which patients' bleeding may have worse outcomes could be related to incomplete evacuation of shed blood from around the heart and lungs in the early hours after heart surgery. There are potentially several causes of incomplete evacuation of shed blood. Recent surveys and a prospective observational study demonstrated that chest tube clogging is more common than previously appreciated, suggesting that inadequate blood evacuation leading to retained blood from around the heart and lungs also may be affecting outcomes in patients who bleed after heart surgery. ${ }^{14,15}$ Furthermore, chest tubes might be positioned inefficiently, may be removed too early, or may become kinked or bent when needed for drainage. If shed blood is incompletely evacuated, blood can be retained around the heart and lungs, which could adversely affect outcomes. To explore this hypothesis further, the objective of this study was to determine the incidence of interventions for retained blood in a large cardiac surgery database and examine, using logistic regression analysis, whether this is an independent variable contributing to adverse clinical outcomes in patients recovering after heart surgery.

\section{MATERIALS AND METHODS}

This was a cross-sectional, observational study derived from our institutional clinical databases. With the written consent of the federal data protection officer and the hospital ethics commission (EA1/034/13), clinical routine data from all patients who underwent cardiac surgery between 2006 and 2013 were extracted from the 2 electronic patient data management systems at our hospital (COPRA System, Sasbachwalden, Germany, and SAP, Walldorf, Germany) into an anonymized study database. Because of the study's retrospective design, the ethics commission waived the need for informed consent for this study. Cardiac surgery was defined as a documented procedure on valves or vessels in proximity to the heart or coronary vessels. All patients received $30 \mathrm{~F}$ chest tubes. Pleural tubes were placed when the pleural space was opened. On rare occasions, Jackson-Pratt drains were used. The average number of chest tubes per patient was 1.71. Anticoagulation after surgery is managed per institutional protocol. Six hours after ICU admission, aspirin (100 mg) and low-dose heparin (250 IE/h) are given when the patient is judged hemodynamically stable with no signs of bleeding $(<100 \mathrm{~mL} / \mathrm{h}$ drainage output) and when laboratory results do not suggest coagulation disturbance. To capture the most clinically significant patient population with the primary end point, retained blood was defined as any intervention to remove blood, blood clot, or bloody fluid, such as interventions for tamponade or pericardial effusion, hemothorax, or pleural effusion during the index hospitalization. This included any reexploration for bleeding (which uniformly requires washout of retained blood), any pericardial window or pericardiocentesis, or any placement of a chest tube in the pleural space or thoracentesis. Excluded were reoperations after the index cardiac surgery procedure when bleeding and washout were not managed. When one of these prerequisites was present, the patient was attributed to the "retained blood" group and compared with patients not presenting with any of the defined criteria. Primary end points were in-hospital mortality and length of hospital stay. Time to extubation, incidence of any renal replacement therapy (ie, hemofiltration or hemodialysis), and postoperative transfusion of packed red blood cells were defined as secondary end points. Institutional transfusion triggers follow written, standard operating procedures whereby patients receive transfusion at a trigger of $7 \mathrm{~g} / \mathrm{dL}$ after revascularization. For those who are not completely revascularized, we use a trigger of $8 \mathrm{~g} / \mathrm{dL}$. In case of massive transfusion, we aim for a hemoglobin level of 7 to $9 \mathrm{~g} / \mathrm{dL}$. These policies did not change during the 7 -year study period. ${ }^{16}$

In addition to basic patient characteristics, type, priority, and duration of surgery as markers of its complexity and preoperative risk (Age, Creatinine, and Ejection Fraction ${ }^{17}$ ), and postoperative Acute Physiology and Chronic Health Evaluation II admission score were assessed to characterize the study population and to identify possible confounders. Preexisting medical conditions were derived from International Classification of Diseases, 10th Revision-coded diagnoses available from the patient data management systems or paper-based patient records. Hemostatic disorder was defined as prothrombin time ratio less than $60 \%$, partial thromboplastin time greater than 45 seconds, or thrombocytes less than $100,000 / \mu \mathrm{L}$.

\section{Statistical Analysis}

Descriptive analyses and statistical testing were performed using the $\mathrm{R}$ Project of Statistical Computing 3.0.1. When normal distribution was ruled out using the Kolmogorov-Smirnov test, results were given as medians and interquartile ranges, and otherwise as mean \pm standard deviation. Qualitative observations were characterized by numbers with percentage. Statistical significance among groups was analyzed univariately by the exact nonparametric Kruskal-Wallis test and (pairwise) with the exact MannWhitney $U$ test. Exact chi-square tests were used for qualitative data. Separate multivariate logistic regressions were performed for any of the defined study end points, adjusted for possible preoperative and perioperative confounding factors with stepwise backward selection. Whenever the response variable was continuous (eg, length of hospital stay), the median of the study population served as cutoff point. Odds ratios (ORs) with $95 \%$ confidence intervals (CIs) were determined and used for graphical presentation. In addition, continuous variables were analyzed using robust regression with Huber function. All regression models are reported in Tables E1 and E2. Logistic regression analyses were completed by a 
TABLE 1. Basic patient characteristics

\begin{tabular}{|c|c|c|c|c|c|}
\hline & $\begin{array}{c}{[\text { ALL] }} \\
\mathbf{N}=6909\end{array}$ & $\begin{array}{c}\text { No retained blood } \\
\quad \mathbf{N}=\mathbf{5 5 9 3}\end{array}$ & $\begin{array}{c}\text { Retained blood } \\
\quad \mathrm{N}=1316\end{array}$ & $\boldsymbol{P}$ & $\mathbf{n}$ \\
\hline \multicolumn{6}{|l|}{ Basic data } \\
\hline Age, $y$ & $69.0[61.0-75.0]$ & $69.0[61.0-74.0]$ & $71.0[64.0-77.0]$ & $<.001$ & 6909 \\
\hline Sex: F & $1964(28.4 \%)$ & $1524(27.2 \%)$ & $440(33.4 \%)$ & $<.001$ & 6909 \\
\hline BMI & $26.9[24.3-30.1]$ & $27.0[24.4-30.2]$ & $26.3[23.8-29.7]$ & .001 & 5168 \\
\hline \multicolumn{6}{|l|}{ Preexisting medical conditions } \\
\hline Coronary heart disease & $5383(77.9 \%)$ & $4418(79.0 \%)$ & $965(73.3 \%)$ & $<.001$ & 6909 \\
\hline Left heart failure (>NYHA II) & $2069(29.9 \%)$ & $1487(26.6 \%)$ & $582(44.2 \%)$ & $<.001$ & 6909 \\
\hline COPD & $1184(17.1 \%)$ & $879(15.7 \%)$ & $305(23.2 \%)$ & $<.001$ & 6909 \\
\hline Endocrine disease & $6334(91.7 \%)$ & $5074(90.7 \%)$ & $1260(95.7 \%)$ & $<.001$ & 6909 \\
\hline Peripheral vascular disease & $1333(19.3 \%)$ & $1006(18.0 \%)$ & $327(24.8 \%)$ & $<.001$ & 6909 \\
\hline Atrial fibrillation & $2054(29.7 \%)$ & $1432(25.6 \%)$ & $622(47.3 \%)$ & $<.001$ & 6909 \\
\hline Chronic renal insufficiency & $1684(24.4 \%)$ & $1234(22.1 \%)$ & $450(34.2 \%)$ & $<.001$ & 6909 \\
\hline Hematocrit preoperatively & $41.0[37.0-43.0]$ & $41.0[38.0-44.0]$ & $39.0[35.0-43.0]$ & $<.001$ & 4382 \\
\hline Hemostatic disorder & $754(10.9 \%)$ & $570(10.2 \%)$ & $184(14.0 \%)$ & $<.001$ & 6909 \\
\hline Antiaggregation & & & & .044 & 5072 \\
\hline Mono antiplatelet therapy & $2309(45.5 \%)$ & $1950(46.3 \%)$ & $359(41.7 \%)$ & & \\
\hline Dual antiplatelet therapy & $1097(21.6 \%)$ & $903(21.4 \%)$ & $194(22.6 \%)$ & & \\
\hline
\end{tabular}

$F$, Female; BMI, body mass index; NYHA, New York Heart Association; COPD, chronic obstructive pulmonary disease

graphical method for verifying the assumed linear relationship between the LOGIT and the influencing continuous variables. ${ }^{18}$ Details on missing data have been reported in Tables 1 and 2. No specific measures were undertaken regarding regression analyses, such as imputation. All tests should be understood as constituting explorative analysis; no adjustment for multiple testing has been made.

\section{RESULTS}

During the 8-year study period from 2006 to 2013, 6909 adult patients underwent cardiac surgery and qualified for study inclusion. By using the definition of retained blood, 1316 patients $(19 \%)$ had 1 or more intervention to remove blood, blood clot, or bloody fluid from around the heart and lungs. This included patients who had interventions for pericardial effusion $(\mathrm{n}=135,1.95 \%)$, tamponade $(\mathrm{n}=34,0.49 \%)$, thoracentesis $(\mathrm{n}=588,8.51 \%)$, or hemothorax $(\mathrm{n}=212$, $3.07 \%)$, and 476 patients $(6.9 \%)$ who were returned to the operating room for bleeding and washout of hematoma. Patients in the retained blood group had an average of 1.7 conditions that were part of the composite. The median number of days to retained blood interventions was 4 days postoperatively $(0-11)$. The median time to thoracentesis was postoperative day 10 (5-17).

Table 1 shows the baseline patient characteristics and preexisting medical conditions. Patients in the retained blood group were slightly older, and the percentage of female patients was higher than in the other group. Except for coronary heart disease, all medical conditions that had been assessed were more frequently found in the retained blood group. Preoperative anticoagulation did not differ between groups.

As shown in Table 2, the distribution of surgical procedures in both groups was significantly different. Whereas more patients in the nonretained blood group underwent coronary artery bypass grafting $(\mathrm{CABG})$ surgery, $\mathrm{CABG}$ and valve surgery were equally distributed in the retained blood group. Also, combined procedures (ie, CABG and valves) were performed more often in patients in the retained blood group. Patients undergoing isolated CABG had a retained blood rate of $15 \%$ (577/3954), patients undergoing isolated valve CABG had a retained blood rate of 24\% (501/2093), and patients undergoing combined CABG/valve surgery had a retained blood rate of $28 \%$ (238/862). Likewise, priority of surgery affected the rate of retained blood. Elective cases had a retained blood rate of $22 \%(962 / 4361)$, urgent cases had a retained blood rate of 64\% (332/519), and emergency cases had a retained blood rate of $55 \%(436 / 795)$. Because determinants that are generally associated with compromised outcome (ie, longer duration of surgery, emergency interventions, transfusion) were more often found in the retained blood group, we performed a subanalysis to investigate whether the occurrence of retained blood was predictable from patients' preoperative and perioperative characteristics. A HosmerLemeshow test with a $P$ value less than .001 of the respective logistic regression model did not suggest any sufficient calibration with those factors.

Hemodynamic instability and higher 24-hour chest tube outputs were more often noted in the retained blood group. In particular, patients in that group had lower mean arterial pressure (69.6 [64.7-76.7] $\mathrm{mm} \mathrm{Hg}$ vs 72.1 [66.2-78.3] mm $\mathrm{Hg}, P<.001)$ and more often required norepinephrine $(72.3 \%$ vs $52.5 \%, P<.001)$ and epinephrine $(42.4 \%$ vs $17.7 \%, P<.001)$ during the first 24 hours after surgery.

Parameters on patient outcome are shown in Table 3. Inhospital mortality was significantly higher in patients in the 
TABLE 2. Surgery-related data and presence of factors of the retained blood definition

\begin{tabular}{|c|c|c|c|c|c|}
\hline & $\begin{array}{c}{[A L L]} \\
N=6909\end{array}$ & $\begin{array}{l}\text { No retained blood } \\
\quad \mathbf{N}=\mathbf{5 5 9 3}\end{array}$ & $\begin{array}{l}\text { Retained blood } \\
\quad \mathbf{N}=1316\end{array}$ & $\boldsymbol{P}$ & $\mathbf{n}$ \\
\hline \multicolumn{6}{|l|}{ Surgery } \\
\hline Type of surgery & & & & $<.001$ & 6909 \\
\hline CABG & $3954(57.2 \%)$ & $3377(60.4 \%)$ & $577(43.8 \%)$ & & \\
\hline Valves & $2093(30.3 \%)$ & $1592(28.5 \%)$ & $501(38.1 \%)$ & & \\
\hline Both & $862(12.5 \%)$ & $624(11.2 \%)$ & $238(18.1 \%)$ & & \\
\hline Duration of surgery, min & $195[160-240]$ & $195[160-235]$ & $200[160-255]$ & $<.001$ & 5706 \\
\hline Priority of surgery & & & & $<.001$ & 5675 \\
\hline Elective & $4361(76.8 \%)$ & $3606(79.0 \%)$ & $755(68.1 \%)$ & & \\
\hline Urgent & $519(9.15 \%)$ & $394(8.63 \%)$ & $125(11.3 \%)$ & & \\
\hline Emergency & $795(14.0 \%)$ & $566(12.4 \%)$ & $229(20.6 \%)$ & & \\
\hline pRBC transfusion (pat. \%) & $1829(29.6 \%)$ & $1320(26.2 \%)$ & $509(44.5 \%)$ & $<.001$ & \\
\hline $\mathrm{pRBC}$ transfusion, units & $1.95(1.05)$ & $1.88(0.97)$ & $2.16(1.23)$ & $<.001$ & 6181 \\
\hline ACEF score & $1.28[1.13-1.60]$ & $1.27[1.12-1.54]$ & $1.42[1.22-1.95]$ & $<.001$ & 6181 \\
\hline APACHE II & $18.0[14.0-24.0]$ & $18.0[14.0-23.0]$ & $21.0[16.0-27.0]$ & $<.001$ & 4915 \\
\hline Retained blood-related factors & & & & & 5763 \\
\hline Pericardial effusion & $135(1.95 \%)$ & $0(0.00 \%)$ & $135(10.3 \%)$ & & 6909 \\
\hline Hemothorax & $212(3.07 \%)$ & $0(0.00 \%)$ & $212(16.1 \%)$ & & 6909 \\
\hline Tamponade & $34(0.49 \%)$ & $0(0.00 \%)$ & $34(2.58 \%)$ & & 6909 \\
\hline Thoracentesis & $588(8.51 \%)$ & $0(0.00 \%)$ & $588(44.7 \%)$ & & 6909 \\
\hline
\end{tabular}

$C A B G$, Coronary artery bypass grafting; $p R B C$, packed red blood cells; $A C E F$, Age, Creatinine, and Ejection Fraction; APACHE, Acute Physiology and Chronic Health Evaluation.

retained blood group $(19.7 \%$ vs $3.9 \%, P<.001)$. Also, length of hospital stay (days) (25 [15-47] vs 12 [9-17], $P<.001)$ and ICU stay (days) $(14$ [7-30] vs 5 [3-7], $P<.001)$ were significantly increased. The time of ventilation was longer (80 [26-308] vs 20 [9-40] hours, respectively, $P<.001)$. Any postoperative renal replacement therapy $(42.1 \%$ vs $10.1 \%, P<.001)$ and transfusion of packed red blood cells $(54.1 \%$ vs $10.0 \%, P<.001)$ were more often required.

Patients in the retained blood group presented a high number of conditions preoperatively and perioperatively that may have had a negative impact on patient outcome. In multivariate regression analyses, retained blood was associated with an OR of 4.041 (95\% CI, 2.589-6.351; $P<.001)$ for in-hospital mortality. A length of stay more than 13 days in hospital (OR, 3.853; 95\% CI, 2.882$5.206, P<.001)$ or 5 days in the ICU (OR, 4.602; $95 \%$ CI, 3.449-6.183; $P<.001)$ was associated with a 5-fold risk in patients in the retained blood group. Time of ventilation more than 23 hours had an OR of 3.596 (95\% CI, 2.690-4.851; $P<.001$ ), and incidence of hemodialysis had an OR of 4.449 (95\% CI, 3.188-6.226; $P<.001)$. Patients in the retained blood group had a 6-fold risk of requiring packed red blood cell transfusion postoperatively (OR, 6.261; 95\% CI, 4.628-8.481; $P<.001$ ). A summary of ORs is graphically presented in Figure 1. Additional multivariate analyses of the study's continuous end points yielded that retained blood was associated with a 10.6day increment of a patient's hospital stay (95\% CI, 9.50511.768; $P<.001)$ and a 5.0-day increment of ICU stay (95\% CI, 4.477-5.494; $P<.001)$. Time of ventilation increased by 24.3 hours (95\% CI, 21.208-27.470; $P<.001)$. A complete list of adjusted confounders and individual regression models is available in Table E1.

\section{DISCUSSION}

In our own earlier research, we found that bleeding, as measured by the volume of chest tube output, was

TABLE 3. Patient outcomes

\begin{tabular}{|c|c|c|c|c|}
\hline & $\begin{array}{c}{[\text { ALL] }} \\
\mathbf{N}=6909\end{array}$ & $\begin{array}{c}\text { No retained blood } \\
\quad \mathbf{N}=\mathbf{5 7 8 4}\end{array}$ & $\begin{array}{l}\text { Retained blood } \\
\quad \mathrm{N}=1316\end{array}$ & $P$ \\
\hline Mortality (in-hospital) & $475(6.88 \%)$ & $216(3.86 \%)$ & $259(19.7 \%)$ & $<.001$ \\
\hline LOS (hospital) [d] & $13.0[9.00-21.0]$ & $12.0[9.00-17.0]$ & $25.0[15.0-47.0]$ & $<.001$ \\
\hline $\operatorname{LOS}(\mathrm{ICU})[\mathrm{d}]$ & $5.00[3.00-9.00]$ & $5.00[3.00-7.00]$ & $14.0[7.00-30.0]$ & $<.001$ \\
\hline Time of ventilation $[\mathrm{h}]$ & $23.0[10.0-54.0]$ & $20.0[9.00-40.0]$ & $80.0[26.0-308]$ & $<.001$ \\
\hline Incidence of hemodialysis & $1117(16.2 \%)$ & $563(10.1 \%)$ & $554(42.1 \%)$ & $<.001$ \\
\hline Postoperative transfusion (pRBC) & $1273(18.4 \%)$ & $561(10.0 \%)$ & $712(54.1 \%)$ & $<.001$ \\
\hline
\end{tabular}

$L O S$, Length of stay; $I C U$, intensive care unit; $p R B C$, packed red blood cells. 


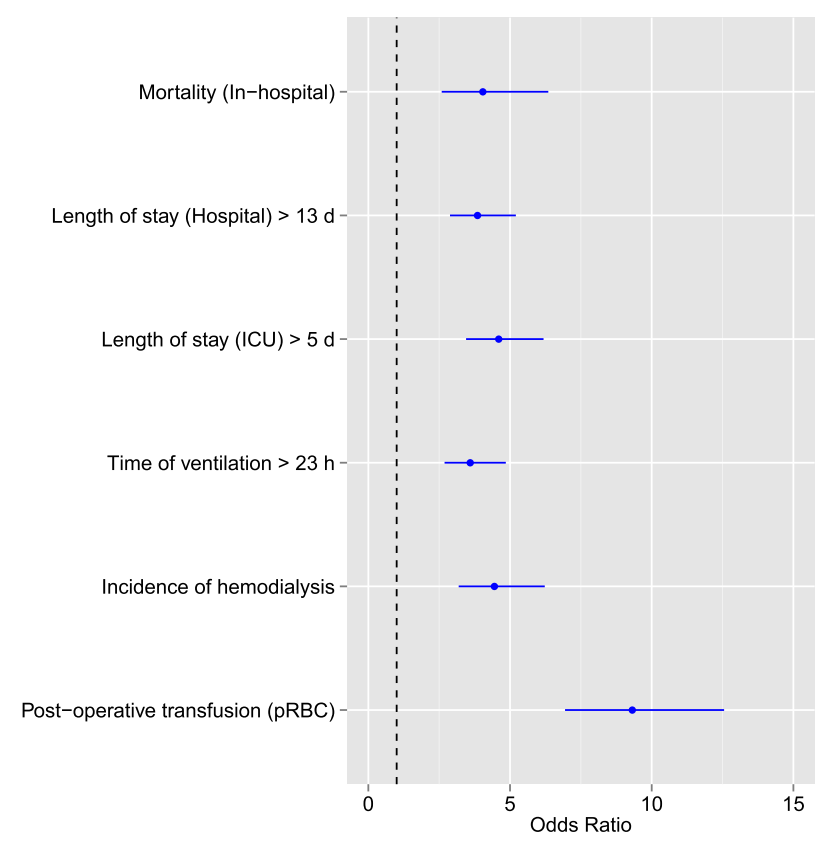

FIGURE 1. Graphical presentation of ORs of selected outcome parameters of retained blood patients versus control. Each ratio presents the result of a separate logistic regression with differing explanatory variables as determined by stepwise backwards selection. Whenever the response variable was continuous (eg, length of hospital stay), the median of the study population served as cutoff point. ICU, Intensive care unit; $p R B C$, packed red blood cells.

associated with higher 30-day mortality, higher incidence of stroke, ICU stay more than 72 hours, mechanical ventilation more than 24 hours, and significantly increased costs. ${ }^{6,19}$ Dixon and colleagues ${ }^{12}$ similarly showed that the volume of chest tube drainage was significantly associated with adverse outcomes, including duration of hospital and ICU stay, duration of mechanical ventilation, and rates of pneumonia, septicemia, hemofiltration, tracheostomy, reintubation, and readmission to the ICU after ward discharge. ${ }^{12}$ They concluded that the extent of chest tube drainage had a dose-dependent relationship with the extent of decrease in cardiac index and impairment in respiratory function in the ICU. ${ }^{12}$ Why patients who bleed have far worse outcomes is still a subject of debate.

One critical and perhaps overlooked aspect of the management of a bleeding patient is the absolute requirement to evacuate the shed blood from around the heart and lungs in the early hours of recovery in the ICU. We and others hypothesized that an additional mechanism by which bleeding patients may have poor outcomes could be related to inadequate chest tube drainage leading to retained blood. ${ }^{12}$ Because of the volumetrically confined mediastinal, pericardial, and pleural spaces that contain the heart and lungs, any bleeding must be promptly externalized with drainage tubes to avoid internal bleeding that is not evacuated or recognized. Chest tubes placed around the heart and lungs fitted to suction canisters are used in all patients to remove this blood to keep the heart decompressed in the pericardium and prevent compression of the lungs that can impair respiratory function during early recovery. Clinicians caring for patients after heart surgery are well aware that chest tubes can clog, and when they do, adverse patient outcomes can ensue. ${ }^{15}$ Prospective studies have shown that chest tubes can become clogged with blood, impairing drainage in up to $36 \%$ of patients. ${ }^{14}$ When clogging of a chest tube occurs while a patient is still bleeding, the shed blood can be retained around the heart and lungs. This raises the possibility that chest tube clogging leading to retained blood may contribute to poor outcomes in patients recovering from heart surgery. However, the incidence and consequences of retained blood have never been studied. In addition, chest tubes can be placed in a way they are not in continuity with a source of bleeding or become kinked or bent, providing other mechanisms for incomplete evacuation of shed blood during early recovery.

To explore this hypothesis further, we set out to determine the incidence and clinical consequences for patients who require additional interventions for retained blood after heart surgery. Our impression was that there was a continuum of patients with retained blood from those who present with enough retained blood to trigger a return to the operating room for reexploration and washout of clot to those who present later with bloody effusions around the heart and lungs. To minimize the potential to overestimate the incidence in patients with clinically insignificant retained blood, we focused on patients who required specific interventions to remove blood clot, blood, or bloody effusion during a return to the operating room for reexploration for bleeding with washout or during additional drainage procedures for blood or bloody effusions, such as a pericardial window, pericardiocentesis, pleural chest tube placement, or thoracentesis. Using a definition whereby a specific coded procedural intervention is required to remove retained blood was thought to be more accurate and clinically relevant than diagnosis codes because many patients can have diagnostic codes for small effusions that do not turn out to be clinically relevant.

In this study, 1316 of 6909 patients $(19.0 \%)$ required a retained blood-related intervention during early recovery from heart surgery. Patients with retained blood were noted to be significantly older and more likely female, and to have lower body mass index. They were also more likely to have left ventricular failure, chronic obstructive pulmonary disease, renal insufficiency, lower hematocrits, and hemostatic disorders preoperatively. This suggests that high-risk patients experience this outcome more commonly than low-risk patients. However, we were able to rule out these confounding factors in multivariate analyses, showing that retained blood was an independent predictor for worse outcome in all defined end points. Furthermore, we were 
able to show that the incidence of retained blood was not predictable by a patient's preoperative and perioperative characteristics. Likewise, we found that although patients who bleed more are more likely to develop retained blood, bleeding does not allow prediction of retained blood in multivariate analysis.

Although many studies have focused on the need to reexplore patients to repair bleeding sources and wash out retained blood, our study reveals an important number of patients who have a more subacute form of retained blood, that is, bloody effusions around the heart and lungs that require interventions for drainage. Numerous studies have shown that most effusions presenting in this time frame early after surgery are bloody, exudative, and inflammatory, providing a link in many cases with retained blood and the subsequent development of effusions. ${ }^{20-24}$ Occasionally, they can be from other causes, such as heart failure. Likewise, early pericardial effusions are generally always bloody, suggesting a similar cause related to retained blood. ${ }^{25-27}$ The high incidence of effusions requiring intervention after cardiac surgery suggests that targeting chest tube management and retained blood for quality improvement also may affect these outcomes.

Given the impact that retained blood has on clinical outcomes, this raises the question if we are doing enough to maximize blood evacuation for patients bleeding after cardiac surgery. Although there can be numerous causes of incomplete blood evacuation, one item that might contribute in some cases is impaired chest tube patency. Currently there are no published guidelines on best practices to maintain chest tube patency after cardiac surgery. Chest tube manipulations, such as chest tube stripping or milking, are commonly performed, but their safety and efficacy have been questioned. ${ }^{28}$ Day and colleagues ${ }^{29}$ reviewed the subject and found little evidence to support the efficacy of chest tube manipulations to maintain patency. They concluded that these practices may be harmful because of negative pressures generated from this technique. Opening chest tubes and inserting items to break up a clot are impractical for routine use and have safety concerns. ${ }^{30,31}$ Recently available techniques to actively clear chest tubes without breaking the sterile seal may allow routine chest tube clearance that could reduce retained blood. ${ }^{32,33}$ In a study by Sirch and colleagues, ${ }^{34}$ using the same definition of retained blood, maintaining chest tube patency reduced this complication by $43 \%$ in propensitymatched patients.

\section{Study Limitations}

The present analysis has several limitations that are important to acknowledge. This was a retrospective analysis and therefore subject to investigator bias and errors in manual extraction from the medical records. In addition, not all the relevant factors, such as findings at reexploration for retained blood or the cytology of fluid removed by thoracentesis, were available for this analysis. The documentation of retained blood relied on specifically coded interventions in the medical records and therefore is an accurate measure of clinically significant retained blood. Given the reliance on coded interventions for retained blood, and not, for example, imaging studies, we may have underestimated the real incidence of retained blood because some patients may have had retained blood that did not require an intervention. To obtain the most accurate estimation of the impact of retained blood on outcomes, subsequent studies may be required to examine for more subtle forms of retained blood that do not require an intervention, such as those noted on imaging studies only. In addition, we did not differentiate the results in regard to the causes of bleeding (ie, examined whether the cause of bleeding was surgical or caused by coagulopathy or if tamponade was present on reexploration). ${ }^{1,34,35}$ Further, it should be noted that this study was not designed to draw definitive conclusions on the link of chest tube clogging with retained blood and did not evaluate whether preventing chest tube clogging might reduce this complication. However, the authors believe that the high incidence of retained blood and the link with adverse outcomes and mortality should draw attention to the importance of adequate blood evacuation in the early recovery after heart surgery.

\section{CONCLUSIONS}

Retained blood after cardiac surgery is common and significantly associated with higher in-hospital mortality and other postoperative complications. It is worse in higher-risk patients who bleed more, but it cannot be entirely predicted and can occur in any category of patient. Incomplete evacuation of shed blood is a potentially readily addressable problem that may be targeted through protocols and quality-improvement initiatives in the ICU.

\section{Conflict of Interest Statement}

E.M.B. is a consultant and stock shareholder in ClearFlow, Inc. ClearFlow Inc, was not involved in the data collection, analysis, or drafting of the manuscript and had no role in the conclusions from this research. M.S. reports consulting fees from Masimo and rationpharm, and lecture fees from Edwards, Pulsion Medical Systems, Fresenius Medical, and Clearflow. All other authors have nothing to disclose with regard to commercial support.

\footnotetext{
References

1. Sniecinski RM, Levy JH. Bleeding and management of coagulopathy. J Thorac Cardiovasc Surg. 2011;142:662-7.

2. Moulton MJ, Creswell LL, Mackey ME, Cox JL, Rosenbloom M. Reexploration for bleeding is a risk factor for adverse outcomes after cardiac operations. $J$ Thorac Cardiovasc Surg. 1996;111:1037-46.

3. Berger JS, Herout PM, Harshaw Q, Steinhubl SR, Frye CB, Becker RC. Bleeding-associated outcomes with preoperative clopidogrel use in on- and off-pump coronary artery bypass. J Thromb Thrombolysis. 2012;34:56-64.
} 
4. Dacey LJ, Munoz JJ, Baribeau YR, Johnson ER, Lahey SJ, Leavitt BJ, et al. Reexploration for hemorrhage following coronary artery bypass grafting: incidence and risk factors. Northern New England Cardiovascular Disease Study Group. Arch Surg. 1998;133:442-7.

5. Kinnunen EM, Juvonen T, Airaksinen KE, Heikkinen J, Kettunen U, Mariscalco G, et al. Clinical significance and determinants of the universal definition of perioperative bleeding classification in patients undergoing coronary artery bypass surgery. J Thorac Cardiovasc Surg. 2014;148:1640-6.e2.

6. Christensen MC, Dziewior F, Kempel A, von Heymann C. Increased chest tube drainage is independently associated with adverse outcome after cardiac surgery. J Cardiothorac Vasc Anesth. 2012;26:46-51.

7. Ranucci M, Bozzetti G, Ditta A, Cotza M, Carboni G, Ballotta A. Surgical reexploration after cardiac operations: why a worse outcome? Ann Thorac Surg. 2008;86:1557-62.

8. Vivacqua A, Koch CG, Yousuf AM, Nowicki ER, Houghtaling PL, Blackstone EH, et al. Morbidity of bleeding after cardiac surgery: is it blood transfusion, reoperation for bleeding, or both? Ann Thorac Surg. 2011;91:1780-90.

9. Murphy GJ, Reeves BC, Rogers CA, Rizvi SI, Culliford L, Angelini GD. Increased mortality, postoperative morbidity, and cost after red blood cell transfusion in patients having cardiac surgery. Circulation. 2007;116:2544-52.

10. Carson JL, Brooks MM, Abbott JD, Chaitman B, Kelsey SF, Triulzi DJ, et al. Liberal versus restrictive transfusion thresholds for patients with symptomatic coronary artery disease. Am Heart J. 2013;165:964-71.e1.

11. Murphy GJ, Pike K, Rogers CA, Wordsworth S, Stokes EA, Angelini GD, et al. Liberal or restrictive transfusion after cardiac surgery. N Engl J Med. 2015;372: 997-1008.

12. Dixon B, Santamaria JD, Reid D, Collins M, Rechnitzer T, Newcomb AE, et al. The association of blood transfusion with mortality after cardiac surgery: cause or confounding? Transfusion. 2013;53:19-27.

13. Hajjar LA, Vincent JL, Galas FR, Nakamura RE, Silva CM, Santos MH, et al. Transfusion requirements after cardiac surgery: the TRACS randomized controlled trial. JAMA. 2010;304:1559-67.

14. Karimov JH, Gillinov AM, Schenck L, Cook M, Kosty Sweeney D, Boyle EM, et al. Incidence of chest tube clogging after cardiac surgery: a single-center prospective observational study. Eur J Cardiothorac Surg. 2013;44:1029-36.

15. Shalli S, Saeed D, Fukamachi K, Gillinov AM, Cohn WE, Perrault LP, et al. Chest tube selection in cardiac and thoracic surgery: a survey of chest tuberelated complications and their management. J Card Surg. 2009;24:503-9.

16. Spies C, Kastrup M, Kerner T, Melzer-Gartzke C, Zielke H, Kox WJ. Sops in Intensivmedizin und Notfallmedizin: Alle Relevanten Standards und Techniken Für die Klinik. Stuttgart, Germany: Georg Thieme Verlag; 2013.

17. Ranucci M, Castelvecchio S, Conte M, Megliola G, Speziale G, Fiore F, et al. The easier, the better: age, creatinine, ejection fraction score for operative mortality risk stratification in a series of 29,659 patients undergoing elective cardiac surgery. J Thorac Cardiovasc Surg. 2011;142:581-6.

18. Vittinghoff E, Glidden DV, Shiboski SC. Regression Methods in Biostatistics. New York, NY: Springer; 2012.

19. Christensen MC, Krapf S, Kempel A, von Heymann C. Costs of excessive postoperative hemorrhage in cardiac surgery. J Thorac Cardiovasc Surg. 2009;138: 687-93.
20. Light RW. Pleural effusions after coronary artery bypass graft surgery. Curr Opin Pulm Med. 2002;8:308-11.

21. Peng MC, Hou CJ, Li JY, Hu PY, Chen CY. Prevalence of symptomatic large pleural effusions first diagnosed more than 30 days after coronary artery bypass graft surgery. Respirology. 2007;12:122-6.

22. Lehto J, Gunn J, Karjalainen P, Airaksinen J, Kiviniemi T. Incidence and risk factors of postpericardiotomy syndrome requiring medical attention: the Finland Postpericardiotomy Syndrome Study. J Thorac Cardiovasc Surg. 2015;149: 1324-9.

23. Sadikot RT, Rogers JT, Cheng DS, Moyers P, Rodriguez M, Light RW. Pleural fluid characteristics of patients with symptomatic pleural effusion after coronary artery bypass graft surgery. Arch Intern Med. 2000;160:2665-8.

24. Labidi M, Baillot R, Dionne B, Lacasse Y, Maltais F, Boulet LP. Pleural effusions following cardiac surgery: prevalence, risk factors, and clinical features. Chest 2009;136:1604-11.

25. Angelini GD, Penny WJ, el-Ghamary F, West RR, Butchart EG, Armistead SH et al. The incidence and significance of early pericardial effusion after open heart surgery. Eur J Cardiothorac Surg. 1987;1:165-8.

26. Ashikhmina EA, Schaff HV, Sinak LJ, Li Z, Dearani JA, Suri RM, et al. Pericardial effusion after cardiac surgery: risk factors, patient profiles, and contemporary management. Ann Thorac Surg. 2010;89:112-8.

27. Gercekoglu H, Aydin NB, Dagdeviren B, Ozkul V, Sener T, Demirtas M, et al. Effect of timing of chest tube removal on development of pericardial effusion following cardiac surgery. J Card Surg. 2003;18:217-24.

28. Halm MA. To strip or not to strip? Physiological effects of chest tube manipulation. Am J Crit Care. 2007;16:609-12.

29. Day TG, Perring RR, Gofton K. Is manipulation of mediastinal chest drains useful or harmful after cardiac surgery? Interact Cardiovasc Thorac Surg. 2008;7 888-90.

30. Boyacioglu K, Kalender M, Ozkaynak B, Mert B, Kayalar N, Erentug V. A new use of Fogarty catheter: chest tube clearance. Heart Lung Circ. 2014;23: e229-30.

31. Halejian BA, Badach MJ, Trilles F. Maintaining chest tube patency. Surg Gynecol Obstet. 1988;167:521.

32. Arakawa Y, Shiose A, Takaseya T, Fumoto H, Kim HI, Boyle EM, et al. Superior chest drainage with an active tube clearance system: evaluation of a downsized chest tube. Ann Thorac Surg. 2011;91:580-3.

33. Perrault LP, Pellerin M, Carrier M, Cartier R, Bouchard D, Demers P, et al. The PleuraFlow active chest tube clearance system: initial clinical experience in adult cardiac surgery. Innovations (Phila). 2012;7:354-8.

34. Sirch J, Ledwon M, Puski T, Boyle EM, Pfeiffer S, Fischlein T. Active clearance of chest drainage catheters reduces retained blood. J Thorac Cardiovasc Surg. 2016;151:832-8.e2.

35. Loor G, Vivacqua A, Sabik JF III, Li L, Hixson ED, Blackstone EH, et al. Proces improvement in cardiac surgery: development and implementation of a reoperation for bleeding checklist. J Thorac Cardiovasc Surg. 2013;146:1028-32.

Key Words: retained blood, pleural effusion, tamponade, reexploration, pericardial effusion, chest tube 
TABLE E1. Logistic regression models of dichotomous and dichotomized outcome parameters. Stepwise backwards variable selection was conducted in a regression model containing the following parameters: age, sex, BMI, type of surgery, priority of surgery, duration of surgery, ACEF risk score, perioperative transfusion of pRBC, coronary heart disease, left heart failure (NYHA >II), COPD, peripheral vascular disease, atrial fibrillation, chronic renal insufficiency, endocrine disease, hematocrit preoperative, hemostatic disorder, antiaggregation, and Acute Physiology and Chronic Health Evaluation II on ICU admission

\begin{tabular}{|c|c|c|c|}
\hline & $\boldsymbol{P}$ & OR & 95\% CI \\
\hline \multicolumn{4}{|l|}{ Mortality } \\
\hline Retained blood & $<.001$ & 4.041 & $2.589-6.351$ \\
\hline Age (y) & .014 & 1.036 & $1.008-1.066$ \\
\hline BMI & .100 & 1.037 & $0.993-1.082$ \\
\hline Valves (CABG) & .124 & 1.528 & $0.890-2.635$ \\
\hline $\mathrm{CABG}+$ valves $(\mathrm{CABG})$ & .047 & 1.784 & $1.005-3.157$ \\
\hline Duration of surgery (min) & $<.001$ & 1.006 & $1.003-1.008$ \\
\hline $\mathrm{ACEF}$ & .055 & 1.526 & $0.985-2.339$ \\
\hline $\mathrm{pRBC}$ transfusion perioperative (unit) & $<.001$ & 1.448 & $1.230-1.703$ \\
\hline COPD & .132 & 1.449 & $0.886-2.329$ \\
\hline Peripheral vascular disease & .007 & 1.997 & $1.198-3.271$ \\
\hline Atrial fibrillation & .004 & 1.969 & $1.235-3.150$ \\
\hline Chronic renal insufficiency & .022 & 0.555 & $0.331-0.911$ \\
\hline Hemostatic disorder & .034 & 1.707 & $1.032-2.785$ \\
\hline APACHE II on ICU admission & $<.001$ & 1.097 & $1.062-1.134$ \\
\hline \multicolumn{4}{|l|}{ Length of stay (hospital) $>23 \mathrm{~d}$} \\
\hline Retained blood & $<.001$ & 3.853 & $2.882-5.206$ \\
\hline Valves (CABG) & $<.001$ & 1.859 & $1.460-2.372$ \\
\hline $\mathrm{CABG}+$ valves $(\mathrm{CABG})$ & $<.001$ & 1.724 & $1.274-2.338$ \\
\hline Urgent (elective) & .118 & 0.761 & $0.540-1.069$ \\
\hline Emergency (elective) & .147 & 0.719 & $0.457-1.119$ \\
\hline Duration of surgery (m) & .035 & 1.002 & $1.000-1.003$ \\
\hline $\mathrm{ACEF}$ & .003 & 1.397 & $1.124-1.740$ \\
\hline $\mathrm{pRBC}$ transfusion perioperative (unit) & .037 & 1.134 & $1.008-1.277$ \\
\hline COPD & .020 & 1.361 & $1.051-1.765$ \\
\hline Atrial fibrillation & $<.001$ & 1.953 & $1.548-2.468$ \\
\hline Chronic renal insufficiency & .004 & 1.438 & $1.126-1.836$ \\
\hline Endocrine disease & .146 & 1.328 & $0.909-1.954$ \\
\hline Hematocrit preoperatively & .104 & 1.019 & $0.996-1.044$ \\
\hline Hemostatic disorder & .001 & 1.600 & $1.208-2.124$ \\
\hline Antiaggregation mono & .052 & 1.249 & $0.999-1.564$ \\
\hline Antiaggregation dual & .004 & 1.544 & $1.152-2.071$ \\
\hline \multicolumn{4}{|l|}{ Length of stay $(\mathrm{ICU})>5 \mathrm{~d}$} \\
\hline Retained blood & $<.001$ & 4.602 & $3.449-6.183$ \\
\hline Age (y) & .094 & 1.010 & $0.998-1.022$ \\
\hline Urgent (elective) & .728 & 1.067 & $0.738-1.534$ \\
\hline Emergency (elective) & .005 & 1.920 & $1.211-3.037$ \\
\hline Duration of surgery (m) & $<.001$ & 1.006 & $1.004-1.008$ \\
\hline $\mathrm{ACEF}$ & .001 & 1.526 & $1.184-1.969$ \\
\hline pRBC transfusion perioperative (unit) & .006 & 1.174 & $1.047-1.317$ \\
\hline Left heart failure (>NYHA II) & $<.001$ & 2.998 & $2.357-3.822$ \\
\hline Atrial fibrillation & $<.001$ & 2.162 & $1.700-2.750$ \\
\hline Chronic renal insufficiency & .043 & 1.303 & $1.007-1.684$ \\
\hline Endocrine disease & $<.001$ & 2.284 & $1.460-3.661$ \\
\hline Hemostatic disorder & .022 & 1.403 & $1.049-1.876$ \\
\hline APACHE II on ICU admission & .021 & 1.020 & $1.003-1.037$ \\
\hline \multicolumn{4}{|l|}{ Time of ventilation $>23 \mathrm{~h}$} \\
\hline Retained blood & $<.001$ & 3.596 & $2.690-4.851$ \\
\hline Age (y) & .007 & 1.015 & $1.004-1.027$ \\
\hline BMI & $<.001$ & 1.050 & $1.029-1.072$ \\
\hline Urgent (elective) & .080 & 1.363 & $0.964-1.933$ \\
\hline
\end{tabular}


TABLE E1. Continued

\begin{tabular}{|c|c|c|c|}
\hline & $\boldsymbol{P}$ & OR & $\mathbf{9 5} \% \mathrm{CI}$ \\
\hline Emergency (elective) & .095 & 1.445 & $0.938-2.231$ \\
\hline Duration of surgery $(\mathrm{m})$ & $<.001$ & 1.007 & 1.006-1.009 \\
\hline $\mathrm{ACEF}$ & .053 & 1.265 & $0.998-1.607$ \\
\hline pRBC transfusion perioperative (unit) & .118 & 0.916 & $0.820-1.022$ \\
\hline Left heart failure (>NYHA II) & $<.001$ & 2.473 & $1.948-3.148$ \\
\hline COPD & .038 & 1.326 & $1.017-1.733$ \\
\hline Peripheral vascular disease & .013 & 1.426 & $1.079-1.887$ \\
\hline Atrial fibrillation & .072 & 1.234 & $0.981-1.552$ \\
\hline APACHE II on ICU admission & $<.001$ & 1.035 & $1.019-1.052$ \\
\hline \multicolumn{4}{|l|}{ Incidence of hemodialysis } \\
\hline Retained blood & $<.001$ & 4.449 & $3.188-6.226$ \\
\hline Age (y) & .003 & 0.973 & $0.955-0.990$ \\
\hline BMI & .007 & 1.045 & $1.012-1.079$ \\
\hline Valves (CABG) & .048 & 1.470 & $1.002-2.154$ \\
\hline $\mathrm{CABG}+$ valves $(\mathrm{CABG})$ & .075 & 1.482 & $0.958-2.280$ \\
\hline Duration of surgery (min) & $<.001$ & 1.008 & $1.006-1.011$ \\
\hline ACEF & $<.001$ & 3.029 & $2.222-4.145$ \\
\hline $\mathrm{pRBC}$ transfusion perioperative (unit) & .007 & 1.223 & $1.057-1.413$ \\
\hline Atrial fibrillation & $<.001$ & 2.516 & $1.787-3.546$ \\
\hline Chronic renal insufficiency & $<.001$ & 2.672 & $1.900-3.760$ \\
\hline Endocrine disease & .003 & 4.589 & $1.832-13.415$ \\
\hline Hematocrit preoperatively & .013 & 0.959 & $0.927-0.991$ \\
\hline Hemostatic disorder & .070 & 1.423 & $0.967-2.078$ \\
\hline APACHE II on ICU admission & $<.001$ & 1.108 & $1.082-1.136$ \\
\hline
\end{tabular}

$O R$, Odds ratio; $C I$, confidence interval; $B M I$, body mass index; $C A B G$, coronary artery bypass grafting; $A C E F, A$ ge, Creatinine, and Ejection Fraction; $p R B C$, packed red blood cells; $C O P D$, chronic obstructive pulmonary disease; $A P A C H E$, Acute Physiology and Chronic Health Evaluation; $I C U$, intensive care unit; NYHA, New York Heart Association. 
TABLE E2. Robust regression models of continuous outcome parameters. The same variables were considered as for logistic regression.

\begin{tabular}{|c|c|c|c|c|c|}
\hline & Estimate & SE & $\mathbf{t}$ & $\boldsymbol{P}$ & $95 \% \mathrm{CI}$ \\
\hline \multicolumn{6}{|l|}{ Length of stay (hospital) } \\
\hline Intercept & 12.265 & 2.992 & 4.099 & $<.001$ & $6.396-18.133$ \\
\hline Age (y) & -0.035 & 0.022 & -1.619 & .106 & -0.078 to 0.007 \\
\hline Sex (female) & 0.377 & 0.462 & 0.816 & .415 & -0.529 to 1.283 \\
\hline BMI & 0.066 & 0.041 & 1.628 & .104 & -0.014 to 0.146 \\
\hline Valves (CABG) & 2.609 & 0.761 & 3.430 & .001 & $1.117-4.101$ \\
\hline $\mathrm{CABG}+$ valves $(\mathrm{CABG})$ & 2.058 & 0.607 & 3.393 & .001 & $0.869-3.248$ \\
\hline Urgent (elective) & -0.983 & 0.674 & -1.458 & .145 & -2.305 to 0.339 \\
\hline Emergency (elective) & -1.056 & 0.855 & -1.235 & .217 & -2.733 to 0.621 \\
\hline Duration of surgery (m) & 0.011 & 0.003 & 3.425 & .001 & $0.005-0.017$ \\
\hline $\mathrm{ACEF}$ & 1.045 & 0.48 & 2.178 & .030 & $0.104-1.986$ \\
\hline $\mathrm{pRBC}$ transfusion perioperative (unit) & 0.989 & 0.248 & 3.990 & $<.001$ & $0.503-1.475$ \\
\hline Coronary heart disease & 1.042 & 0.798 & 1.306 & .192 & -0.523 to 2.607 \\
\hline Left heart failure (NYHA > II) & 0.613 & 0.467 & 1.312 & .190 & -0.303 to 1.528 \\
\hline COPD & 1.215 & 0.522 & 2.328 & .020 & $0.191-2.239$ \\
\hline Peripheral vascular disease & 0.745 & 0.543 & 1.371 & .170 & -0.32 to 1.81 \\
\hline Atrial fibrillation & 3.722 & 0.478 & 7.781 & $<.001$ & $2.784-4.661$ \\
\hline Chronic renal insufficiency & 1.458 & 0.500 & 2.915 & .004 & $0.477-2.439$ \\
\hline Endocrine disease & 1.397 & 0.741 & 1.885 & .060 & -0.056 to 2.85 \\
\hline Hematocrit preoperatively & 0.043 & 0.048 & 0.912 & .362 & -0.05 to 0.137 \\
\hline Hemostatic disorder & 1.603 & 0.564 & 2.841 & .005 & $0.496-2.71$ \\
\hline Antiaggregation & 0.867 & 0.426 & 2.033 & .042 & $0.031-1.703$ \\
\hline APACHE II on ICU admission & 0.063 & 0.031 & 2.070 & .039 & $0.003-0.124$ \\
\hline Retained blood & 10.637 & 0.577 & 18.438 & $<.001$ & $9.505-11.768$ \\
\hline \multicolumn{6}{|l|}{ Length of stay (ICU) } \\
\hline Intercept & 3.196 & 1.29 & 2.478 & .013 & $0.667-5.726$ \\
\hline Age (y) & -0.002 & 0.009 & -0.255 & .799 & -0.021 to 0.016 \\
\hline Sex (Female) & 0.103 & 0.199 & 0.519 & .604 & -0.287 to 0.494 \\
\hline BMI & 0.016 & 0.018 & 0.911 & .363 & -0.019 to 0.051 \\
\hline Valves (CABG) & 0.230 & 0.330 & 0.698 & .485 & -0.417 to 0.878 \\
\hline $\mathrm{CABG}+$ valves $(\mathrm{CABG})$ & 0.384 & 0.264 & 1.455 & .146 & -0.134 to 0.902 \\
\hline Urgent (elective) & 0.455 & 0.294 & 1.549 & .122 & -0.121 to 1.032 \\
\hline Emergency (elective) & 1.254 & 0.376 & 3.336 & .001 & $0.517-1.992$ \\
\hline Duration of surgery (m) & 0.012 & 0.001 & 8.786 & $<.001$ & $0.009-0.015$ \\
\hline ACEF & 0.701 & 0.208 & 3.364 & .001 & $0.292-1.11$ \\
\hline $\mathrm{pRBC}$ transfusion perioperative (unit) & 0.313 & 0.106 & 2.949 & .003 & $0.105-0.52$ \\
\hline Coronary heart disease & 0.191 & 0.349 & 0.547 & .584 & -0.493 to 0.874 \\
\hline Left heart failure (NYHA > II) & 1.842 & 0.205 & 8.991 & $<.001$ & $1.44-2.244$ \\
\hline COPD & 0.366 & 0.227 & 1.610 & .107 & -0.08 to 0.812 \\
\hline Peripheral vascular disease & 0.170 & 0.237 & 0.716 & .474 & -0.295 to 0.634 \\
\hline Atrial fibrillation & 1.735 & 0.210 & 8.256 & $<.001$ & $1.323-2.148$ \\
\hline Chronic renal insufficiency & 0.543 & 0.216 & 2.512 & .012 & $0.119-0.967$ \\
\hline Endocrine disease & 1.034 & 0.317 & 3.264 & .001 & $0.413-1.655$ \\
\hline Hematocrit preoperatively & -0.010 & 0.021 & -0.498 & .618 & -0.051 to 0.03 \\
\hline Hemostatic disorder & 0.840 & 0.244 & 3.437 & .001 & $0.361-1.319$ \\
\hline Antiaggregation & 0.066 & 0.185 & 0.356 & .722 & -0.297 to 0.428 \\
\hline APACHE II on ICU admission & 0.039 & 0.013 & 2.925 & .003 & $0.013-0.065$ \\
\hline Retained blood & 4.985 & 0.259 & 19.236 & $<.001$ & $4.477-5.494$ \\
\hline \multicolumn{6}{|l|}{ Time of ventilation } \\
\hline Intercept & -12.014 & 7.813 & -1.538 & .124 & -27.336 to 3.308 \\
\hline Age (y) & 0.023 & 0.057 & 0.41 & .682 & -0.088 to 0.135 \\
\hline Sex (female) & 1.386 & 1.206 & 1.149 & .251 & -0.98 to 3.751 \\
\hline BMI & 0.490 & 0.108 & 4.539 & $<.001$ & $0.278-0.701$ \\
\hline Valves (CABG) & 3.125 & 2.010 & 1.555 & .120 & -0.816 to 7.067 \\
\hline $\mathrm{CABG}+$ valves $(\mathrm{CABG})$ & 3.543 & 1.625 & 2.18 & .029 & $0.356-6.73$ \\
\hline
\end{tabular}


TABLE E2. Continued

\begin{tabular}{|c|c|c|c|c|c|}
\hline & Estimate & SE & $\mathbf{t}$ & $\boldsymbol{P}$ & $95 \% \mathrm{CI}$ \\
\hline Urgent (elective) & 2.825 & 1.796 & 1.573 & .116 & -0.697 to 6.347 \\
\hline Emergency (elective) & 3.974 & 2.288 & 1.737 & .083 & -0.514 to 8.462 \\
\hline Duration of surgery (m) & 0.091 & 0.009 & 10.528 & $<.001$ & $0.074-0.108$ \\
\hline $\mathrm{ACEF}$ & 2.428 & 1.282 & 1.894 & .058 & -0.085 to 4.942 \\
\hline $\mathrm{pRBC}$ transfusion perioperative (unit) & -0.392 & 0.64 & -0.612 & .541 & -1.647 to 0.864 \\
\hline Coronary heart disease & 3.573 & 2.107 & 1.696 & .090 & -0.559 to 7.705 \\
\hline Left heart failure $(\mathrm{NYHA}>\mathrm{II})$ & 10.073 & 1.26 & 7.991 & $<.001$ & $7.601-12.545$ \\
\hline COPD & 3.543 & 1.393 & 2.543 & .011 & $0.81-6.275$ \\
\hline Peripheral vascular disease & 3.868 & 1.442 & 2.683 & .007 & $1.041-6.696$ \\
\hline Atrial fibrillation & 7.806 & 1.284 & 6.082 & $<.001$ & $5.289-10.323$ \\
\hline Chronic renal insufficiency & 3.599 & 1.315 & 2.736 & .006 & $1.02-6.178$ \\
\hline Endocrine disease & 3.787 & 1.916 & 1.976 & .048 & $0.029-7.545$ \\
\hline Hematocrit preoperatively & -0.028 & 0.126 & -0.225 & .822 & -0.274 to 0.218 \\
\hline Hemostatic disorder & -1.665 & 1.476 & -1.128 & .259 & -4.559 to 1.229 \\
\hline Antiaggregation & 1.411 & 1.119 & 1.261 & .207 & -0.784 to 3.606 \\
\hline APACHE II on ICU admission & 0.288 & 0.080 & 3.581 & $<.001$ & $0.13-0.445$ \\
\hline Retained blood & 24.339 & 1.596 & 15.246 & $<.001$ & $21.208-27.47$ \\
\hline
\end{tabular}

$S E$, Standard error; $C I$, confidence interval; $B M I$, body mass index; $C A B G$, coronary artery bypass grafting; $A C E F$, Age, Creatinine, and Ejection Fraction; $p R B C$, packed red blood cells; NYHA, New York Heart Association; COPD, chronic obstructive pulmonary disease; APACHE, Acute Physiology and Chronic Health Evaluation; ICU, intensive care unit. 